\title{
MATE PREFERENCES AMONG HADZA HUNTER-GATHERERS
}

\author{
Frank W. Marlowe \\ Harvard University
}

\begin{abstract}
The literature on human mate preferences is vast but most data come from studies on college students in complex societies, who represent a thin slice of cultural variation in an evolutionarily novel environment. Here, I present data on the mate preferences of men and women in a society of hunter-gatherers, the Hadza of Tanzania. Hadza men value fertility in a mate more than women do, and women value intelligence more than men do. Women place great importance on men's foraging, and both sexes rate character as important. Unlike college students, Hadza men place considerable importance on women being hard-working, and Hadza women cite looks about as often as men do.
\end{abstract}

KEY WORDS: Evolutionary psychology; Hadza; Hunter-gatherers; Mate preferences

Reproductive success is the ultimate currency in the economy of natural selection. Consequently, we should be good at evaluating potential mates and prefer those traits most likely to enhance our own reproductive success. So what are those traits? Could they be greatly different now than they were prior to agriculture? To the extent they are the same, is it because they are still good predictors of reproductive success or simply an inherited legacy? Many studies have found considerable overlap in the preferences of men and women, as well as significant differences (Buss 1989; Ellis 1992; Perrett et al. 1999; Townsend and Wasserman 1998). However, most of these studies have been conducted on college students, who represent a thin slice of cultural variation in an evolutionarily novel environment. There have been few studies on other types of populations (Jones 1996; Sprecher et al. 1994), and very few on hunter-gatherers

Received October 21, 2003; accepted January 10, 2004; revised version received February 8,2004

Address all correspondence to Frank W. Marlowe, Department of Anthropology, Harvard University, Cambridge, MA 02138,USA. Email: fmarlowe@fas.harvard.edu

Copyright $\odot 2004$ by Aldine Transaction, New Jersey

Human Nature, Vol. 15, No. 4, pp. 365-376.

$1045-6767 / 98 / \$ 6.00+.15$ 
(Jones and Hill 1993) who might exhibit preferences more akin to those that prevailed prior to agriculture and social complexity and stratification. Here I present data on mate preferences in one of the few remaining hunter-gatherer societies, the Hadza of Tanzania.

\section{THE HADZA}

The Hadza live in a savanna-woodland habitat in northern Tanzania. They number about one thousand, of whom 300-400 are full-time foragers and among whom this study was conducted. Women dig wild tubers, gather berries, and collect baobab fruit, while men primarily collect wild honey and hunt mammals and birds with bows and arrows. When medium to large game is brought into camp it is shared quite evenly across households (Hawkes et al. 2001b), and despite the fact that some men are much better hunters than others, there is no clear dominance or status hierarchy. Males bring into camp about $43 \%$ of daily calories, but among married couples about $50 \%$ and among those with nursing infants about $65 \%$ (Marlowe 2003).

Median age at first marriage is 21 years for men and 17 years for women. Marriages are not arranged so both sexes are free to choose their spouses, though they do seek the approval of their parents. Marriage means simply that a couple has begun living together, which usually follows a brief, somewhat discreet courtship. When females are about 17 or 18 , and before they get married for the first time, they may be courted by more than one male. When this happens, it can lead to a violent, even fatal, conflict. Because of the danger, others sometimes get involved and ask the woman to choose one suitor rather than keep stringing both along, but young women appear to want to shop before marrying.

Monogamy is the norm, with only about $4 \%$ of men having two wives at once, and those marriages often do not last long (Marlowe 2003). The divorce rate is fairly high, especially in the first marriages (Blurton Jones et al. 2000), so serial monogamy is the best way to describe the mating system. However, perhaps $20 \%$ of Hadza stay married to the same person their whole life. Divorce often results when a man is pursuing an extramarital affair that his wife will not tolerate. If he is gone from camp too many days his wife may hear gossip and suspect he is seeing another woman and decide the marriage is over. When the husband returns he may find that she has a new husband, but he may still consider her his wife. Female extramarital affairs appear to be mostly cases like this.

The Hadza live in camps that average about 25 people, but membership is continually changing as people move in and out. Camps are moved to a different location about every month or two. People also frequently 
visit other camps so they know a great deal about who is living where, which is probably important when seeking mates. Sometimes a person in a larger camp can find a suitable mate within the camp. But often camps are so small that he or she will have to find someone in another camp. Males will often go to visit a camp where an unmarried female lives and then just end up staying there if she reciprocates his interest. Marital residence is flexible, but it is more common for a couple to live with the kin of the wife than the husband (Blurton Jones et al. 2004; Marlowe 2004; Woodburn 1968).

There is very little intermarriage with other ethnic groups, so most Hadza know everyone in their mate pool very well, something that was probably true throughout much of our evolutionary history but is not true in complex, industrial societies. It is more common for Hadza women than men to marry into a different ethnic group. However, many of these marriages do not last, and women often return to live in a Hadza camp even when they have children by a non-Hadza man. Such children are considered Hadza, and such women do not appear to be stigmatized. It seems that a common cause of women returning is that they dislike the way they are treated by non-Hadza men. Hadza women have a good deal of independence and often speak their minds.

Men who have better hunting reputations have greater reproductive success, and have wives who are younger in relation to themselves, than men with poorer hunting reputations (Marlowe 2000). If men prefer younger wives with greater residual reproductive value, then the fact that better hunters have younger wives suggests that better hunters may have higher mate value and greater choice of mates. However, why better hunters might have higher mate value is the subject of considerable debate. The long-held view that women should prefer to marry better hunters because they and their children would thereby receive more provisioning has been challenged on the grounds that big game meat is shared evenly across households in camp (Hawkes et al. 2001b), which means a woman married to a poor hunter gets as much as a woman married to a good hunter. An alternative explanation argues that women might prefer to marry better hunters because hunting success could be a reliable sign of a man's overall quality, for example, his health, vigor, coordination, or intelligence (Hawkes and Bliege Bird 2002).

\section{METHODS}

During 1995, 1996, and 1997, I interviewed the majority of all Hadza adults in several different camps ( 46 men and 39 women). The 85 people 
reported on here represent about half the total adult population of fulltime foragers. Interviews were conducted individually in Swahili, which all but a few Hadza speak fluently as a second language. Because the Hadza have no written language, they are not able to fill out anonymous forms or use a Likert scale. For this reason, I simply asked males and females what traits are important in a spouse and let them cite as many traits as they wished. I asked, "If you were looking for a husband (wife), what kind of man (woman) would you want? What is important to you?"

Because the open-ended question yielded a wide range of specific traits, answers were later condensed into the following variables: Foraging, Looks, Character, Fertility, Fidelity, Intelligence, and Youth. These seven were the minimum number of categories within which the various answers appeared to fall (Table 1). The open-ended question was the most practical way to elicit preferences since my goal was to learn, rather than prejudge, what traits are important.

When a woman said she wanted a man who is a good hunter or who can feed her children, these answers were coded as "Foraging." When a man said he wanted a woman who can get a lot of food, or who always fetches water and firewood, these answers were also coded as "Foraging." All traits that were clearly attributes of the body or the face were classified as "Looks" (though face was also analyzed separately). My category "Character" includes not only answers like "good character" but also other, more specific traits, such as "nice" (see Table 1), and "nice" was also analyzed separately.

If someone named two traits that were later condensed into one variable, they got a score of only 1 for that variable. Therefore, all seven variables can only have a value of 0 or 1 for each person, but each person can contribute a 1 to more than one of the seven variables. Mean frequencies of traits were analyzed using Mann-Whitney $U$-tests, Spearman correlations, and binary logistic regressions with variables forced to enter. I also note Hadza men's stated preferences with regard to the size and shape of women's breasts, and men's preferences for women's waist-to-hip ratio depicted in visual stimuli. Finally, I note attitudes regarding polygamy, the most common reasons cited for divorce, and what people said were likely outcomes of discovered affairs.

\section{RESULTS}

Three women could not list any traits of potential spouses and were excluded from the preference results, which therefore include 46 men and 36 women (a few extra people are included in the data on polygamy and 
Table 1. The Traits Mentioned by Hadza as Important in a Potential Spouse, Which Were Then Condensed into the Seven Main Trait Categories

\begin{tabular}{|c|c|c|c|c|c|c|}
\hline Character & Looks & Foraging & Fidelity & Fertility & Intelligence & Youth \\
\hline $\begin{array}{l}\text { Good character } \\
\text { Nice } \\
\text { Won't hit } \\
\text { Compatible } \\
\text { Good heart } \\
\text { Understanding } \\
\text { Gentle } \\
\text { Goes Slowly } \\
\text { Share words } \\
\text { Won't fight } \\
\text { Good person } \\
\text { Good soul } \\
\text { Cares for kids } \\
\text { Not bad words } \\
\text { Can live together } \\
\text { Won't sin } \\
\text { One heart wants }\end{array}$ & $\begin{array}{l}\text { Shorter } \\
\text { Thin } \\
\text { Good body } \\
\text { Big } \\
\text { Big breasts } \\
\text { Good looks } \\
\text { Good teeth } \\
\text { Good genitals } \\
\text { Good appearance } \\
\text { Sexy } \\
\text { Good face }\end{array}$ & $\begin{array}{l}\text { Good hunter } \\
\text { Can get food } \\
\text { Hard worker } \\
\text { Fetch water } \\
\text { Fetch wood } \\
\text { Will feed } \\
\text { Can walkabout } \\
\text { Can help work } \\
\text { Cook }\end{array}$ & $\begin{array}{l}\text { Doesn't want others } \\
\text { Stays home } \\
\text { Good reputation } \\
\text { Likes you } \\
\text { Cares about home } \\
\text { Only wants you }\end{array}$ & $\begin{array}{l}\text { Can have kids } \\
\text { Once have kids } \\
\text { Will have kids } \\
\text { Lots of kids }\end{array}$ & $\begin{array}{l}\text { Intelligence } \\
\text { Think } \\
\text { Smart }\end{array}$ & Young \\
\hline
\end{tabular}


divorce with sample size indicated below). Subjects ranged in age from 13 to 70 years old $($ mean $=33$, s.d. $=12.8)$. The mean age of men $(37)$ was greater than the mean age of women (29), partly because females can be considered adults at a younger age than males, and partly because some older women are more difficult to interview as their Swahili is limited and they are more modest than men. Among the 82 people who listed traits important in a mate, $88 \%$ of the men and $67 \%$ of the women were married at the time of the interviews.

The traits most frequently mentioned overall, in order of frequency, were Character, Foraging, Looks, Intelligence, Fertility, Fidelity, and Youth. The order of traits mentioned by men and women were different, with some traits mentioned at significantly different frequencies (Figure $1)$.

A higher percentage of men than women placed importance on fertility in a potential spouse $(U=671, p=0.013, n=82)$. Many men said with

Figure 1. The percent of Hadza males and females who cited various traits as important in a potential spouse ( $n=82,46$ males, 36 females). The only significant differences between the sexes are in Fertility and Intelligence.

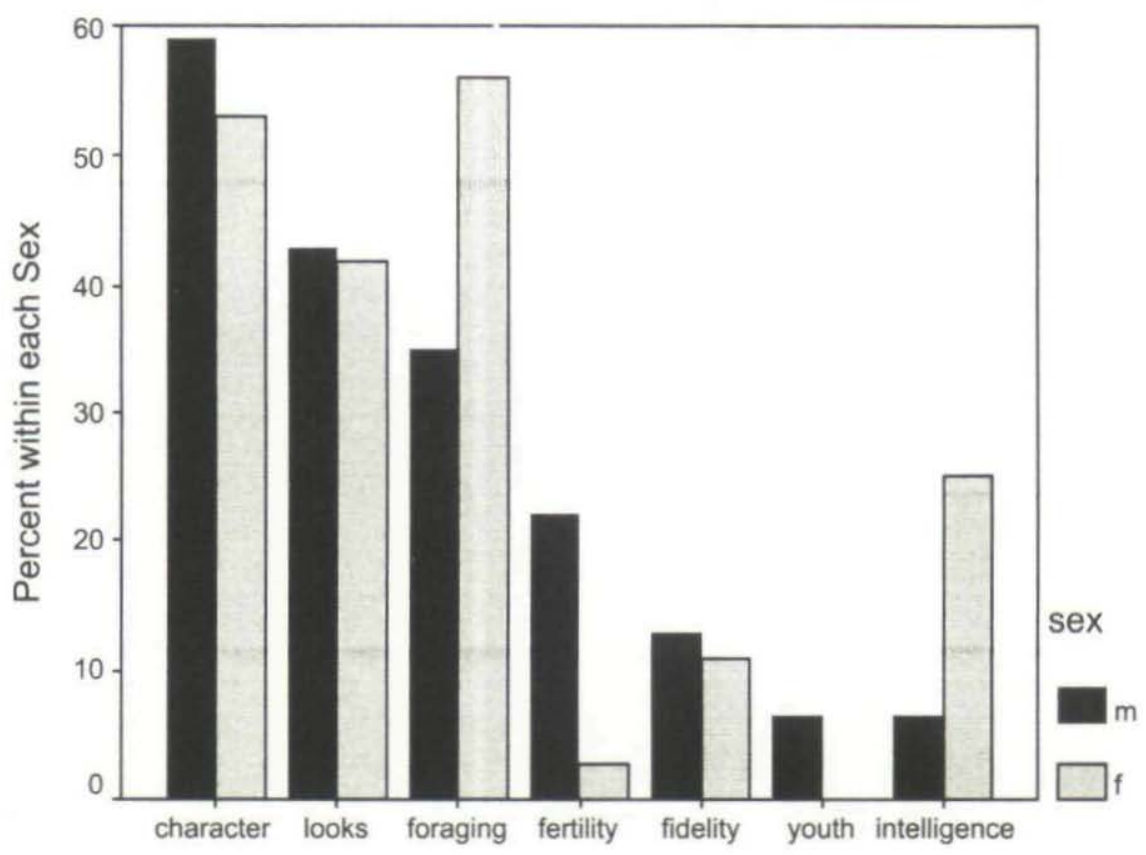

Traits 
great emphasis that it was important that a spouse be able to bear many children. When I asked, "How can you tell?" they would often say you can tell just by looking, though they could not be more specific than that. More women than men placed importance on intelligence $(U=675, p=$ $0.020, n=82$ ).

There were some age-effects on preferences. Older men placed less value on youth $(r=-.352, p=0.016, n=46)$, and less value on looks $(r$ $=-.319, p=0.030, n=46$ ). Older women placed more value on character ( $r=.354, p=0.034, n=36$ ). After controlling for age, "nice" (which, to women, often meant not hitting) was more often valued by women than men $(\beta=2.667, p=0.037$, df $=1)$. After controlling for age, there was still a higher percentage of men than women who placed value on fertility $(\beta=-2.497, p=0.023$, df $=1)$, but no sex difference for intelligence. However, because there was no correlation between a man's age and the value he placed on intelligence, and because it was younger women who valued intelligence more, the difference remains among the younger women who are still in the mate market.

Men who placed importance on fidelity were also more likely to want a good foraging or hard-working wife $(r=.395, p=0.007, n=46)$. Men who valued good looks were likely to also value youth in a wife $(r=.301$, $p=0.042, n=46)$, and less likely to value foraging $(r=-.364, p=0.013$, $n=46)$ and character $(r=-.422, p=0.003, n=46)$. Men who valued character were less likely to value youth $(r=-.315, p=0.033, n=46)$.

Women who placed importance on intelligence were less likely to value character $(r=-610, p<0.0005, n=36)$. For women, good character often meant being nice, and valuing niceness was correlated with valuing fidelity in a husband ( $r=.369, p=0.027, n=36$ ). Among women, placing importance on the face was correlated with placing importance on other traits included in looks $(r=.581, p<0.0005, n=36)$. This correlation was even stronger among men $(r=.793, p<0.0005, n=46)$.

Women did not value looks any less than men. However, given that women's fertility is related to age, which shows in one's appearance, and that men often said you can tell about fecundability by looking at women, it might make sense to combine these into one variable called "appearance." When fertility, youth, and looks were added together (taking a value of $0,1,2$, or 3 ) and age was controlled in a multiple linear regression, men did value appearance more $(\beta=-.290, p=0.011$, $\mathrm{df}=79)$.

When I asked men $(n=32)$ if they found female breasts attractive, $94 \%$ said yes while $6 \%$ said they didn't care about them. Most men who cared about breasts liked them big and round and firm-"like those of young women," they would often say; $70 \%$ used one or more of those 
adjectives while $27 \%$ said all kinds were good and $3 \%$ said they liked small breasts. As reported elsewhere, Hadza men, in contrast to U.S. men (Singh 1993), preferred heavy women over normal and thin women and preferred a high over a low female waist-to-hip ratio (Marlowe and Wetsman 2001).

Significantly more men than women said it was all right for a man to have two wives $65 \%$ vs. $38 \%$ (Mann-Whitney $\mathrm{U}=831, p=.010, n=96$ ). However, older people were more likely to say it was all right $(r=.231$, $p=.023, n=96$ ). After controlling for age, the difference between men and women was just shy of significant $(\beta=-.879, p=.051$, df $=1$ ). No man said it was all right for women to have two husbands, but $19 \%$ of women said it was.

The reason most often cited for couples fighting and divorcing was extramarital affairs. These are not necessarily reasons they themselves fought or divorced but rather reasons they said couples in general fought or divorced. Other reasons cited are listed in Table 2. When I asked, "What happens if someone finds out his or her spouse has had an affair?" $38 \%$ of men and women said the man would try to kill the other man, $26 \%$ said a woman would fight with the other woman, $20 \%$ said a man would leave his wife, and $13 \%$ said the woman would leave her husband $(n=55)$.

\section{DISCUSSION}

In complex societies, several studies have found that women place greater value on a potential long-term mate's education than men do (Buss 1989; Sprecher et al. 1994). Surprisingly few studies have reported on the value placed on intelligence. I could find only two studies reporting on a sex difference in preferences for intelligence. In one (Buunk et al. 2002) women cared about intelligence more than men, whereas in the other $(\mathrm{Li}$ et al. 2002) they did not. Hadza women valued intelligence more than

Table 2. The Percent of Hadza Males and Females Who Cited Various

Reasons for Fighting and/or Divorcing among Couples in General

\begin{tabular}{|l|c|c|c|c|c|c|c|c|c|c|}
\hline Sex & $\begin{array}{l}\text { Extra- } \\
\text { marital } \\
\text { Affairs }\end{array}$ & $\begin{array}{l}\text { Male } \\
\text { extra- } \\
\text { marital } \\
\text { affairs }\end{array}$ & $\begin{array}{l}\text { Female } \\
\text { extra- } \\
\text { marital } \\
\text { affairs }\end{array}$ & $\begin{array}{l}\text { Female } \\
\text { work }\end{array}$ & $\begin{array}{l}\text { Male } \\
\text { work }\end{array}$ & $\begin{array}{l}\text { Strong } \\
\text { words } \\
\text { nagging }\end{array}$ & $\begin{array}{l}\text { No } \\
\text { intel- } \\
\text { igence }\end{array}$ & $\begin{array}{l}\text { Wife } \\
\text { doesn't } \\
\text { want } \\
\text { sex }\end{array}$ & $\begin{array}{l}\text { Disputes } \\
\text { over } \\
\text { Children }\end{array}$ & $\begin{array}{l}\text { Having } \\
\text { No } \\
\text { children }\end{array}$ \\
\hline $\begin{array}{l}\text { Male } \\
\mathrm{n}=42\end{array}$ & 60 & 45 & 29 & 36 & 26 & 19 & 7 & 5 & 0 & 5 \\
\hline $\begin{array}{l}\text { Female } \\
\mathrm{n}=44\end{array}$ & 70 & 64 & 16 & 9 & 7 & 9 & 7 & 2 & 5 & 0 \\
\hline $\begin{array}{l}\text { Total } \\
\mathrm{n}=86\end{array}$ & 65 & 55 & 22 & 22 & 16 & 14 & 7 & 3 & 2 & 2 \\
\hline
\end{tabular}


men, perhaps because it plays a more important role in male-male competition or in male foraging than female foraging. Hadza women who themselves had actually divorced often said that the reason they left their husbands was that they had no intelligence, which also translates as having no sense.

Hadza men valued fertility more than women. They often say they will look for another wife after enduring several years of a childless marriage. Given that female fecundity begins to decline after age 25 (Wood 1994) and ceases at menopause, it is not surprising that some men also mentioned youth whereas no woman did. My impression is that Hadza men, like men in many societies (Kenrick and Keefe 1992; Perusse 1994), seem to prefer women younger than the age of maximum fecundity. When long-term bonds are formed, it pays men to acquire wives who still have most of their reproductive years ahead of them. Hadza men expressed considerable interest in female breasts "like those of pubertal girls." Despite cultural variation in the preferred size, breasts appear to be erotic stimuli, possibly because they reveal a woman's reproductive value (Marlowe 1998).

I suspect that age is more important in any society than it would appear by simply asking people to list traits. For example, when a 35 -year-old man imagines a potential spouse, he may not even consider a 70-year-old woman, and so it does not occur to him to cite age as an important trait. A 35 -year-old woman may not imagine a 15-year-old husband, and therefore may also not think to cite age as important. If we presented people with potential spouses of different ages we might find that age would be the single most important trait when the potential spouse was far too old or far too young.

Hadza men placed considerably more value on a wife being hard-working (and a good forager) than U.S. college men did. Also in contrast to college men (Singh 1993), Hadza men preferred fatter women, and women with a high rather than low waist-to-hip ratio (Marlowe and Wetsman 2001). Hadza men probably preferred fatter women because it is important to store energy for pregnancy and lactation and no foraging woman, certainly no Hadza woman, is ever too fat, a fact that may also explain the Hadza preference for a high waist-to-hip ratio (Marlowe and Wetsman 2001). Unlike women in complex societies (Buss 1989; Sprecher et al. 1994), Hadza women did not value looks significantly less than men did, though if youth and fertility are considered aspects of appearance, they did.

Unlike women in complex societies, Hadza women did not place less value on fidelity than men, which suggests it would cost a woman to share 
a husband or to lose a husband to another woman. In fact, Hadza divorce often occurs when angry wives leave their philandering husbands. On the other hand, married women who have affairs run the risk of being hit or killed by their husbands, so clearly Hadza men care greatly about fidelity, something they may have had in mind when they said good character is important.

Perhaps the most interesting result is that women placed more value on men being good foragers ( $85 \%$ of those women said "good hunter") than on any other trait. This may seem unsurprising to those who assume this explains why women in complex societies place so much value on male occupation and wealth (Buss 1989, 1999). However, the benefit of having a rich husband in agricultural and industrial societies, where resources can go directly to the household, is straightforward. It is less clear what material benefit the wife of a good hunter receives when meat is widely shared with all in camp, as it is among the Hadza and most other foragers (Hawkes et al. 2001a, 2001b). Hadza women's mate preferences suggest they do benefit from having a husband who is a good hunter. This could be because hunting success is a good signal of overall phenotypic quality. But it could also be because Hadza women gain a direct benefit from their husband's provisioning when they are nursing an infant, since at such times they bring in less food and their husbands bring in more food (Marlowe 2003).

It is also interesting that such a high percent of men and women said polygyny is all right, given that there are usually only about $4 \%$ of men with two wives. Even though $38 \%$ of women said it is all right for a man to have two wives, when a married man pursues a second woman and his wife finds out, it usually results in his wife getting angry. I have seen such wives yell and throw things at their husbands. Many men have told me the reason for their divorce was that their wives left them. When I asked why their wives left them, many said with sincere puzzlement, and some sadness, they did not know why. But when I asked if they had started a relationship with their current wife before their previous wife left them, the answer was very often yes. Still puzzled, they would repeat, "I don't know why she left me." These men then had no intention of divorcing; they merely wanted a second woman.

In conclusion, Hadza men want a good-looking, hard-working, fertile, faithful wife and Hadza women want a husband who is a good forager, good looking, intelligent, and faithful. Both sexes value character greatly, which probably reflects their desire for a stable, trustworthy partner. The Hadza are merely one society along the foraging spectrum, but their preferences are likely focused on traits which most impact reproductive suc- 
cess in a niche something like that occupied by humans prior to agriculture and are therefore a valuable case for comparison with the many studies of college students.

This research was made possible by a grant from the National Science Foundation and the Leakey Foundation. I thank the Tanzanian Commission on Science and Technology for permission to conduct research, Professor Audax Mabulla of the University of Dar es Salaam for assistance, the Hanbygotts for hospitality, and the Hadza for their tolerance.

Frank Marlowe (B.A., M.A., M.F.A., Ph.D.) is associate professor in the Department of Anthropology, Harvard University. His research interests include the behavioral ecology of hunter-gatherers, mating systems, parental care, mate choice, and cooperation.

\section{REFERENCES}

Blurton Jones, Nicholas G., Kristen Hawkes, and James F. O'Connell

2004 Hadza Fathers and Grandmothers as Helpers: Residence Data. In Culture,

Ecology and Psychology of Hunter-Gatherer Children, B. S. Hewlett and M. E.

Lamb, eds. In press. New Brunswick, NJ: Aldine-Transaction.

Blurton Jones, Nicholas G., Frank W. Marlowe, Kristen Hawkes, James F. O'Connell 2000 Paternal Investment and Hunter-Gatherer Divorce Rates. In Adaptation and

Human Behavior: An Anthropological Perspective, L. Cronk, N. Chagnon, and

W. Irons, eds. Pp. 69-90. New York: Aldine de Gruyter.

Buss, David M.

1989 Sex Differences in Human Mate Preferences: Evolutionary Hypotheses

Tested in 37 Cultures. Behavioral and Brain Sciences 12:1-49.

1999 Evolutionary Psychology: The New Science of Mind. Boston: Allyn and Bacon.

Buunk, Bram P., P. Dijkstra, D. Fetchenhauer, D. T. Kenrick

2002 Age and Gender Differences in Mate Selection Criteria for Various Involve-

ment Levels. Personal Relationships 9:271-278.

Ellis, Bruce

1992 The Evolution of Sexual Attraction: Evaluative Mechanisms in Women. In

The Adapted Mind, J. Barkow, L. Cosmides, and J. Tooby, eds. Pp. 267-288.

New York: Oxford University Press.

Hawkes, Kristen, and Rebecca Bliege Bird

2002 Showing Off, Handicap Signaling, and the Evolution of Men's Work. Evolutionary Anthropology 11:58-67.

Hawkes, Kristen, James O'Connell, and Nicholas G. Blurton Jones

2001a Hunting and Nuclear Families: Some Lessons from the Hadza about Men's

Work. Current Anthropology 42:681-709.

$2001 \mathrm{~b}$ Hadza Meat Sharing. Evolution and Human Behavior 22:113-142.

Jones, Doug

1996 An Evolutionary Perspective on Physical Attractiveness. Evolutionary

Anthropology 5:97-109. 
Jones, Doug, and Kim Hill

1993 Criteria of Physical Attractiveness in Five Populations. Human Nature 4:271296.

Kenrick, D. T., and R. C. Keefe

1992 Age Preferences in Mates Reflect Sex Differences in Human Reproductive

Strategies. Behavioral and Brain Sciences 15:75-133.

Li, N. P., J. M. Bailey, D. T. Kenrick, J. A. W. Linsenmeier

2002 The Necessities and Luxuries of Mate Preferences: Testing the Tradeoffs.

Journal of Personality and Social Psychology 82:947-955.

Marlowe, Frank W.

1998 The Nubility Hypothesis. Human Nature 9:263-271.

2000 The Patriarch Hypothesis. Human Nature 11:27-42.

2003 A Critical Period for Provisioning by Hadza Men: Implications for Pair

Bonding. Evolution and Human Behavior 24:217-229.

2004 Marital Residence among Foragers. Current Anthropology 45:277-284.

Marlowe, Frank W., and Adam Wetsman

2001 Preferred Waist-to-hip Ratio and Ecology. Personality and Individual

Differences 30:481-489.

Perrett, David, D. Burt, I. Penton-Voak, K. Lee, D. Rowland, R. Edwards

1999 Symmetry and Human Facial Attractiveness. Evolution and Human Behavior 20:295-307.

Perusse, Daniel

1994 Mate Choice in Modern Societies: Testing Evolutionary Hypotheses with

Behavioral Data. Human Nature 5:255-278.

Singh, Devendra

1993 Adaptive Significance of Waist-to-hip Ratio and Female Physical Attrac-

tiveness. Journal of Personality and Social Psychology 65:293-307.

Sprecher, S., Q. Sullivan, and E. Hatfield

1994 Mate Selection Preferences: Gender Differences Examined in a National

Sample. Journal of Personality and Social Psychology 66:1074-1080.

Townsend, J. M., and T. Wasserman

1998 Sexual Attractiveness: Sex Differences in Assessment and Criteria. Evolution and Human Behavior 19:171-191.

Wood, James W.

1994 Dynamics of Human Reproduction: Biology, Biometry, Demography. New York: Aldine de Gruyter.

Woodburn, James

1968 Stability and Flexibility in Hadza Residential Groupings. In Man the Hunter,

R. B. Lee and I. DeVore, eds. Pp. 103-110. Chicago: Aldine. 
Copyright of Human Nature is the property of Transaction Publishers and its content may not be copied or emailed to multiple sites or posted to a listserv without the copyright holder's express written permission. However, users may print, download, or email articles for individual use. 